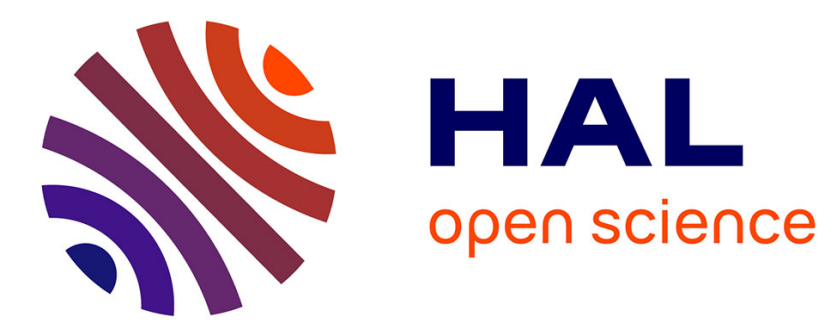

\title{
Both sunitinib and sorafenib are effective treatments for pheochromocytoma in a xenograft model
}

\author{
M. Denorme, Laurent Yon, Clément Roux, B.J. J Gonzalez, Emmanuel \\ Baudin, Y. Anouar, C. Dubessy
}

\section{- To cite this version:}

M. Denorme, Laurent Yon, Clément Roux, B.J. J Gonzalez, Emmanuel Baudin, et al.. Both sunitinib and sorafenib are effective treatments for pheochromocytoma in a xenograft model. Cancer Letters, 2014, 352 (2), pp.236 - 244. 10.1016/j.canlet.2014.07.005 . hal-01706420

HAL Id: hal-01706420

https://hal-normandie-univ.archives-ouvertes.fr/hal-01706420

Submitted on 19 Jul 2018

HAL is a multi-disciplinary open access archive for the deposit and dissemination of scientific research documents, whether they are published or not. The documents may come from teaching and research institutions in France or abroad, or from public or private research centers.
L'archive ouverte pluridisciplinaire HAL, est destinée au dépôt et à la diffusion de documents scientifiques de niveau recherche, publiés ou non, émanant des établissements d'enseignement et de recherche français ou étrangers, des laboratoires publics ou privés. 


\title{
Both sunitinib and sorafenib are effective treatments for pheochromocytoma in a xenograft model
}

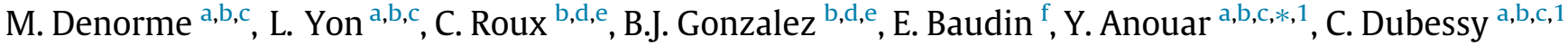 \\ anstitut National de la Santé et de la Recherche Médicale (INSERM), U982, Mont-Saint-Aignan, France \\ ${ }^{\mathrm{b}}$ Normandie Univ, Caen, France \\ ${ }^{\mathrm{C}}$ University of Rouen, Laboratory of Neuronal and Neuroendocrine Differentiation and Communication, Institute for Research and Innovation in Biomedicine (IRIB), \\ Mont-Saint-Aignan, France \\ ${ }^{\mathrm{d}}$ Haute-Normandie-INSERM ERI28, Rouen, France \\ ${ }^{\mathrm{e}}$ University of Rouen, Laboratory of Microvascular Endothelium and Neonate Brain Lesion, Institute for Research and Innovation in Biomedicine, Rouen, France \\ ${ }^{\mathrm{f}}$ Departments of Nuclear Medicine and Endocrine Tumors, Institut Gustave-Roussy, Villejuif, France
}

\section{Introduction}

Pheochromocytomas (PCC) are rare neuroendocrine tumors that arise from chromaffin cells of the adrenal medulla or extraadrenal sites (referred to as paragangliomas). These tumors are characterized by an excess of catecholamine release, leading mainly to hypertension [1]. The other symptoms are variable and nonspecific, including headaches, palpitations, diaphoresis, weight loss and diabetes. The majority of PCC are sporadic, but there is

\footnotetext{
* Corresponding author at: INSERM U982, Lab. Neuronal and Neuroendocrine Differenciation and Communication, University of Rouen, 76821 Mont-SaintAignan, France. Tel.: +33 2351466 61; fax: +33 235146946

E-mail address: youssef.anouar@univ-rouen.fr (Y. Anouar).

1 Y.A. and C.D. should be considered as co-last authors.
}

even so $30-35 \%$ that are associated with an hereditary syndrome due to a germline mutation in one of several susceptibility genes identified to date, including the RET proto-oncogene, the tumor suppressor genes neurofibromin 1 and von Hippel-Lindau (VHL), the subunits of the succinate dehydrogenase (SDHx) enzyme SDHA, B, C, D, and SDHAF2, and the recently discovered TMEM127, MAX and fumarate hydratase [2,3]. Commonly, PCC subtypes can be divided in two clusters based on their gene expression profile. The first cluster of PCC is characterized by mutations in SDHx and VHL genes leading to dysregulation of hypoxia inducible factor-associated pathways and increased angiogenesis [4], while the second cluster is characterized by RET, neurofibromin 1 or TMEM127 mutations which are associated with activation of PI3K/AKT/mTORC and RAS/RAF/ERK pathways [5]. 
While benign tumors are usually resected surgically with a high survival rate for patients, there is no curative treatment for most patients with metastatic PCC. This lack of effective therapy leads to a 5-year mortality rate of 50-60\% [6]. Malignancy occurs in about $15-17 \%$ of PCC cases, but higher proportions have also been reported depending on the location of the primary tumor and the underlying germline mutation $[7,8]$. Nowadays there is still no reliable criterion to diagnose malignancy, except the presence of metastases in lymph nodes, bones, lungs and liver. Among the proposed malignancy indicators, overexpression of vascular endothelial growth factor (VEGF) has been reported [9-11]. VEGF is a pro-angiogenic factor notably secreted by tumor cells, which stimulates the proliferation and migration of endothelial cells resulting in the outgrowth of new capillaries into the tumor. Therefore, the VEGF signaling pathway is essential to neo-angiogenesis which corresponds to the growth of new blood vessels from preexisting vessels. It has been shown that malignant PCC together with SDHx and VHL-related PCC are very highly vascularized tumors with abnormal vascular architecture that is associated with a strong angiogenesis [12-14].

Angiogenesis is a rate-limiting process in tumor growth and malignancy. Targeting neo-vascularization as a therapeutic strategy has led to the development of small specific inhibitors such as sunitinib and sorafenib. These compounds which are receptor tyrosine kinase (RTKs) inhibitors targeting the VEGF signaling pathway [15], have already been evaluated in several clinical trials. Sunitinib inhibits numerous RTKs including VEGFRs, PDGFR, Flt-3, c-kit, CSF-1R, and RET, and has been approved by the Food and Drug Administration (FDA) for the treatment of advanced renal cell carcinoma and gastro-intestinal stromal tumors. Sorafenib inhibits VEGFR-2 and -3, PDGFR-B, Flt-3 and c-kit as well as the raf protein kinase. Sorafenib has also been approved by FDA for the treatment of renal cell carcinoma and hepatocellular carcinoma.

Given the hypervascularization and the significant angiogenesis found in malignant PCC and other PCC subtypes, targeted antiangiogenic therapies have recently been proposed for the treatment of this tumor. Indeed, case reports [16-20] and a clinical study [21] have shown promising results after administration of sunitinib to patients with malignant paraganglioma or PCC. However, these assays only tested sunitinib and have been conducted for some of them on a limited number of patients. In this context, the aim of our study was to provide further pre-clinical evidence for the use of anti-angiogenic treatments for PCC. To achieve this goal, we investigated the action of sunitinib and sorafenib using a PCC cell line and a xenograft mouse model. The effects of both drugs were tested and compared in vivo on tumor growth and neo-angiogenesis, and in vitro on PCC cell survival.

\section{Materials and methods}

Materials

Sunitinib and sorafenib were purchased from LC Laboratories (Woburn, USA). For in vitro studies, they were dissolved in dimethyl sulfoxide (DMSO) at a concentration of $10 \mathrm{mM}$ and then diluted to appropriate final concentrations in Dulbecco's modified Eagle Medium (DMEM, Invitrogen, Cergy Pontoise, France). DMSO did not exceed $0.3 \%$ in the final solution. For in vivo testing, sunitinib and sorafenib were prepared at a final concentration of $8 \mathrm{mg} / \mathrm{mL}$. Sunitinib was diluted in Ora+/water $(1 / 1, v / v$; Paddock Laboratories, Colombes, France) and sorafenib in CremophorEL/ ethanol (1/1, v/v; Sigma-Aldrich, St-Quentin-Fallavier, France) and then diluted in water $(1 / 4, \mathrm{v} / \mathrm{v})$.

\section{PC12 cell culture}

The rat pheochromocytoma-derived, undifferenciated PC12 cells were purchased from the European Collection of Cell Culture (Salisbury, Wilshire, UK) and cultured in DMEM supplemented with $10 \%$ horse serum, $5 \%$ fetal bovine serum,
$1 \%$ L-glutamine and $1 \%$ penicillin-streptomycin in $5 \% \mathrm{CO}_{2} / 95 \% \mathrm{O}_{2}$ humidified atmosphere at $37^{\circ} \mathrm{C}$. Unless otherwise indicated, cell culture reagents were obtained from Sigma-Aldrich.

\section{Cell viability}

PC12 cells were plated at a density of $5 \times 10^{3}$ cells per well in 96-well plate and incubated overnight. On the following day, compounds were added to the wells and incubated for an additional 2-72 h. Cells were cultured in triplicate for each condition and experiments were reproduced 3 times. Cell viability was measured after $72 \mathrm{~h}$ using the CellTiter-Blue Cell Viability Assay kit (Promega, Charbonnière, France) according to the manufacturer's instructions. The $\mathrm{IC}_{50}$ value (half maximal inhibitory concentration) was calculated from dose-response curves by nonlinear regression analysis. Apoptosis was measured from 2 to $24 \mathrm{~h}$ using Apo-ONE ${ }^{\circledR}$ Homogeneous Caspase-3/7 Assay (Promega). Luminescence and fluorescence measurements were performed using the microplate reader FlexStation3 (Molecular Devices, Saint-Grégoire, France).

\section{Animals}

Seven week-old male athymic Swiss nude mice nu/nu (Charles River Laboratory, l'Arbresle, France) were used for in vivo studies. They were housed and maintained under standard laboratory conditions $\left(21^{\circ} \mathrm{C}, 12: 12 \mathrm{~h}\right.$ light-dark cycle) and received food and water ad libitum. Experiments were conducted in accordance with the regional ethics committee on animal experimentation and in compliance with the EC animal welfare regulations.

\section{Mouse xenograft model}

Prior to implantation, PC12 cells were harvested during exponential growth by trypsinization and were then washed thoroughly. Mice received a subcutaneous injection of $5 \times 10^{5}$ cells in a volume of $100 \mu \mathrm{L}$ into the hind flank at day 0 (D0). During the next 14 days, implanted cells grew to form a tumor. When the tumor became measurable (3-4 $\mathrm{mm}^{3}$, around D14), animals were then randomized into control or treated (sunitinib or sorafenib) groups of 10 mice each. Treated mice were daily force-fed with $5 \mu \mathrm{L} / \mathrm{g}$ ( $40 \mathrm{mg} / \mathrm{kg}$ ) of sunitinib or sorafenib during a period of 14 days (D15-D28). This dose was used in several other studies in mice and was chosen because it yields plasma concentrations comparable to those found in patients treated with these drugs [22-24]. Control animals received the vehicle.

Tumor dimensions, assessed using Vernier calipers, and mice body weight were measured three times a week. The tumor volume was calculated using the formula $V=$ width $^{2} \times$ length $\times 0.52$. The relative tumor volume (RTV) was calculated by dividing the tumor volume at any time by the tumor volume at the beginning of the treatment. Tumor growth curves were obtained by plotting the mean RTV against time for each experimental group. The tumor doubling time (TDT) and the tumor growth delay (TGD) were determined using the growth curve part corresponding to the treatment period. TDT was calculated using the equation $T D T=\left(T-T_{0}\right) \times \log 2 / \log V-\log V_{0}$ (where $T-T_{0}$ indicates the duration between two measurements and $V$ and $V_{0}$ denotes the tumor volume at two points of measurement). TGD was calculated as the time, expressed as days, required for tumors to reach a $\mathrm{x}$-fold increase (between 3 and 5 ) in relative tumor volume.

After the treatment period (D28), half of each mice group was euthanized, tumors were excised, frozen at $-25^{\circ} \mathrm{C}$ in isopentane and stored at $-80{ }^{\circ} \mathrm{C}$ until use. The other mice were maintained alive one more week (D35) for tumor growth measurement after treatment withdrawal, and then euthanized.

\section{Immunohistochemistry}

Angiogenesis and apoptosis were investigated by immunohistochemistry. The vascular network was immunolabeled using a rabbit polyclonal CD31 antibody that recognizes endothelial cells (Abcam, Paris, France, diluted 1:300). A cleaved caspase-3 rabbit antibody (Cell Signaling Technology, Saint Quentin Yvelines, France, diluted 1:500) was used to identify apoptotic cells. Frozen tumors were 8-10 $\mu \mathrm{m}$ thick sectioned (Cryostat cryomicrocut 3050, Leica, Solms, Germany), mounted on superfrost slides (Menzel-Glaser, Braunschweig, Germany) and air-dried for $2 \mathrm{~h}$. Sections were fixed in $4 \%$ paraformaldehyde for $20 \mathrm{~min}$, washed twice in phosphate buffered saline (PBS, $\mathrm{pH} 7.4$ ), incubated for $1 \mathrm{~h}$ at room temperature in a blocking buffer and then overnight at $4{ }^{\circ} \mathrm{C}$ with one of the two different primary antibodies. The slides were then washed in PBS and incubated with goat anti-rabbit (GAR)/ Alexa-488 secondary antibody for $2 \mathrm{~h}$ at room temperature. After several rinses in PBS and incubation with the nuclear dye 4,6-diamino-2-phenylindole (DAPI) for $1 \mathrm{~min}$, sections were coverslipped with Fluoroshield mounting medium (SigmaAldrich).

\section{Image analysis}

Image acquisitions were performed with a conventional microscope (Nikon, Champigny-sur-Marne, France). At least 5 animals per group and 2 distant slices per tumor were examined for the quantification of the intratumoral vascularization. 
Five fields were randomly chosen at $20 \times$ magnification excluding the necrotic zone, and stored as TIFF files. In order to obtain objective measurements of the vessels architecture, an automated script was developed using various plug-ins added to Fiji open-source software [25]. Automatically, the macrodetected the labeled tubular structures on acquired images. A stained tube with two end-points was considered as a microvessel. The images were then thresholded to fit with the vascular morphology and to reduce background noise, and the microvascular area was calculated. The thresholded images were then skeletonized to obtain the number and the length of branches, and the number of nodes per microvessel. The data were plotted against treatments.

In order to measure apoptosis, $8 \mu \mathrm{m}$-thick tumor slices were scanned using the Nanozoomer 2.0 HT scanner (Hamamatsu, Massy, France) to get a global view of the caspase-3 labeling. The images were then examined with Fiji software, thresholded and binarized to quantify the global apoptotic staining normalized to the tumor slice area.

\section{Statistical analysis}

Data were plotted and analyzed using the Prism 4 program (GraphPad Software, Inc., San Diego, CA, USA). Non-parametric tests were used to compare the relative tumor volume, tumor weight, caspase-3 labeling (Kruskal-Wallis) and the vascular architecture parameters (Two-Way ANOVA) between controls and treated animals. Probability values $<0.05$ were considered significant.

\section{Results}

Sunitinib and sorafenib inhibit the growth of pheochromocytoma cell xenografts

Oral administration of sunitinib or sorafenib ( $40 \mathrm{mg} / \mathrm{kg} /$ day) for 14 days provoked a significant inhibition of tumor growth in treated compared to control animals (from D28 and D25 until the end of the experiment, respectively, Fig. 1A and B). Tumors from treated animals exhibited a significantly higher TDT than those of the control groups (10.6 days for sunitinib, 7.4 days for sorafenib vs. 5.5 days for controls; $P<0.05$ ). The TGD were 7 and 8 days for sunitinib and sorafenib treatments, respectively. At the end of the experiment, tumor volume was reduced by $60 \%$ after sunitinib treatment $\left(722 \pm 175 \mathrm{~mm}^{3}\right.$ vs. $1765 \pm 378 \mathrm{~mm}^{3}$ at $\left.\mathrm{D} 35, P<0.001\right)$ and by $71 \%$ for sorafenib $\left(478 \pm 83 \mathrm{~mm}^{3}\right.$ vs. $1654 \pm 382 \mathrm{~mm}^{3}$ at D34, $P<0.001)$. As shown in Fig. 1 C and D, the inhibition of tumor growth led to a significant tumor weight loss of $70 \%$ and $73 \%$ after sunitinib (D35) and sorafenib (D34) treatments, respectively $(P<0.05)$.

\section{Sunitinib and sorafenib inhibit tumor neo-angiogenesis in pheochromocytoma cell xenografts}

Macroscopic examination of control tumors at D28 and D34-35 (Fig. 2A and D) showed the occurrence of numerous and thick peritumoral vessels. In contrast, tumors in animals treated with sunitinib (Fig. 2B) or sorafenib (Fig. 2C) were much less surrounded by these vessels than controls. At the end of the experiment, 7 days after the treatment period (D34-35), the number of vessels irrigating the tumors increased again in the previously treated tumors (Fig. 2E and F).

Tumoral neo-angiogenesis was assessed by morphometric analysis of the vascular network after CD31 immunolabeling (Fig. 3). As illustrated in Fig. 3A and D, subcutaneous injection of PC12 cells led to the growth of tumors strongly invaded by microvessels. Control tumors showed a rich vascularization, with a dense network of long and tortuous microvessels (Fig. 3A and D). These vessels displayed linked segments of irregular length, frequently exhibiting 2 or 3 branchings. These tight vascular structures seem to delineate nodules of tumor tissue. In contrast, Fig. 3B and $\mathrm{C}$ show that tumors from treated mice display only a weak vascular network represented by few scattered labeled endothelial cells. However, one week after the treatment period, tumors exhibited again numerous and long vessels (Fig. $3 \mathrm{E}$ and $\mathrm{F}$ ).

Quantitative analysis showed that the microvascular area is drastically reduced by $85 \%$ and $80 \%$ following sunitinib and sorafenib treatment at D28, respectively (Fig. 4A; $P<0.01$ and $P<0.001$, respectively). Both treatments also significantly diminished the number of nodes per field ( $-84 \%$ for sunitinib and $-73 \%$ for sorafenib; Fig. 4B; $P<0.001)$ and the number of branches per field $(-84 \%$ for sunitinib and $-87 \%$ for sorafenib; Fig. $4 C$; $P<0.001)$. Both compounds showed a strong inhibition of the mean vessel length $(-80 \%$ for sunitinib and $-78 \%$ for sorafenib; Fig. 4D; $P<0.01$ and $P<0.001$, respectively). The treatments inhibited the sprouting and the growth of microvessels, as illustrated by Fig. 4E and F which show that sunitinib and sorafenib reduced significantly the number of nodes ( $-95 \%$ and $-84 \% ; P<0.01$ and $P<0.05$, respectively) and branches ( $-30 \%$ and $-27 \% ; P<0.01$ and $P<0.05$, respectively) per microvessel. At the end of the assay, one week after treatment completion (D34-35), all the six parameters analyzed in tumor slices from treated animals were significantly increased compared to D28 values. However, except for the number of branches and nodes per microvessel (Fig. 4E and F), the different parameters including the microvascular area or the length of branches remained significantly reduced compared to control values at D34-35 (Fig. 4A-D).

Sunitinib and sorafenib induce apoptosis in pheochromocytoma cell xenografts

Staining of cleaved caspase-3-positive cells revealed distinct profiles: control tumors were characterized by few and isolated apoptotic cells (Fig. 5A), whereas sunitinib- and sorafenib-treated tumors displayed numerous grouped apoptotic cells (Fig. 5B and C). Indeed, the quantification revealed a significant increase in the surface of apoptotic zones after sunitinib and sorafenib treatment (5.6-fold and 3.5-fold; Fig. 5G; $P<0.01$ and $P<0.001$, respectively). Of note, treatment interruption caused a dramatic decrease in apoptotic levels for both drugs (Fig. 5D-F), which were comparable to those of controls (Fig. $5 \mathrm{G}$ ).

\section{Sunitinib and sorafenib decrease the viability of PC12 cells}

In order to evaluate if sunitinib and sorafenib could have a direct effect on pheochromocytes, cultured PC12 cells were exposed to increasing concentrations of these compounds, and cell viability was assessed after $72 \mathrm{~h}$ exposure (Fig. 6). Sunitinib and sorafenib inhibited PC12 cell viability following biphasic curves, likely reflecting inhibition of proliferation and cytotoxicity. Thus, sunitinib exerted an anti-proliferative effect of $30 \%$ at the nanomolar range $\left(\log \mathrm{IC}_{50}=-7.15 \pm 0.23 ; 0.07 \mu \mathrm{M}\right)$ and a cytotoxic effect at the micromolar range $\left(\log \mathrm{IC}_{5} 0_{2}=-5.36 \pm 0.05 ; 4.35 \mu \mathrm{M}\right)$ (Fig. 6A). Similarly, low doses of sorafenib exerted a $55 \%$ inhibition of cell proliferation $\left(\log \mathrm{IC}_{50} 0_{1}=-7.77 \pm 0.24 ; 0.02 \mu \mathrm{M}\right)$, whereas high doses provoked cytotoxic effects $\left(\log \mathrm{IC} \mathrm{O}_{2}=-4.33 \pm 0.13\right.$; $46.7 \mu \mathrm{M})$ (Fig. 6B).

\section{Sunitinib exerts a pro-apoptotic effect in PC12 cells}

Analysis of PC12 cell apoptosis revealed an effect of sunitinib at a dose of $30 \mu \mathrm{M}$ as early as $4 \mathrm{~h}$ after the onset of the treatment (Fig. 6C). Of note, the apoptotic level at $24 \mathrm{~h}$ is low because the majority of the cells already died at this time point (data not shown). In contrast, whatever the dose and incubation period, sorafenib had no apoptotic effect (Fig. 6D). 

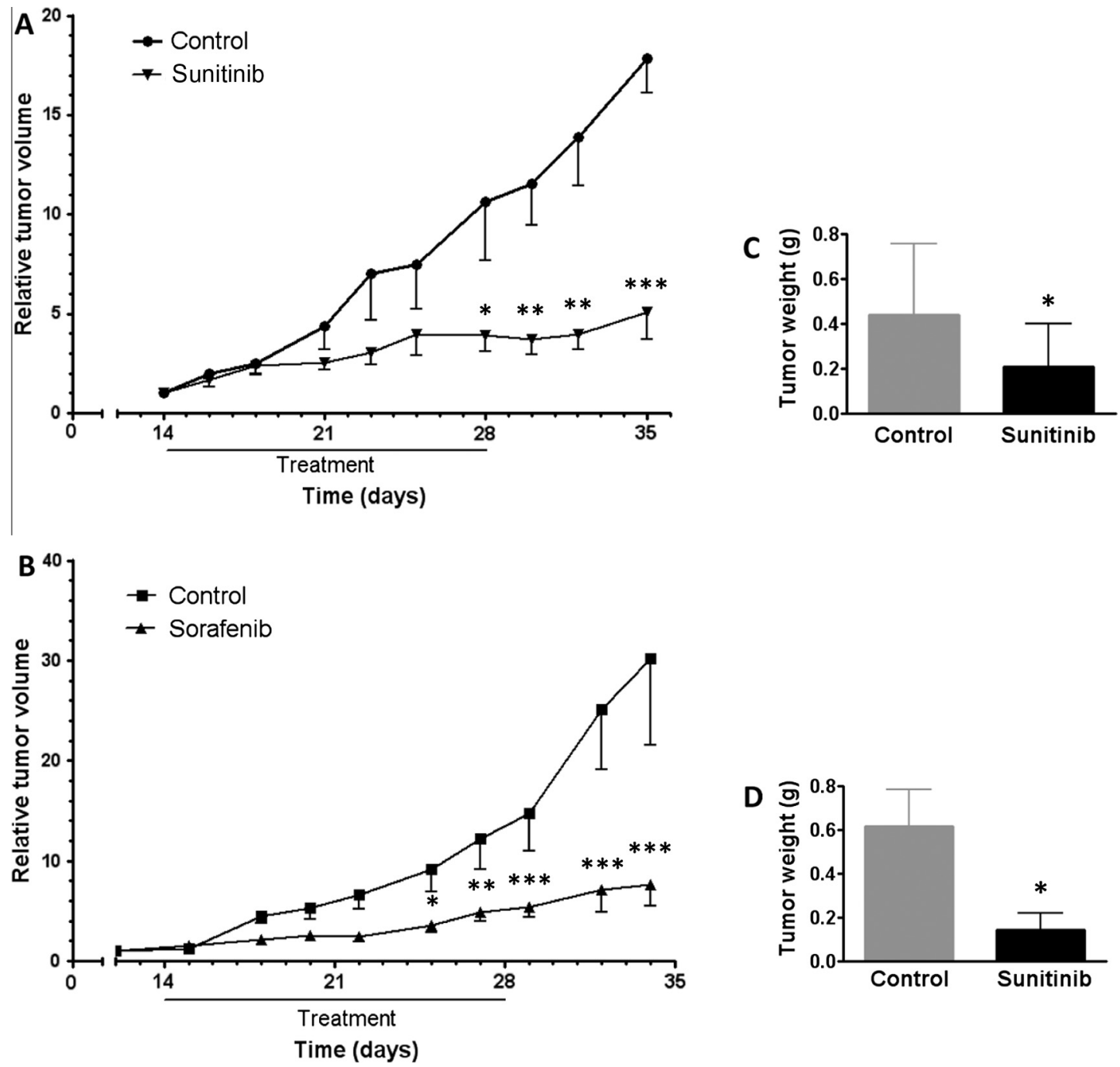

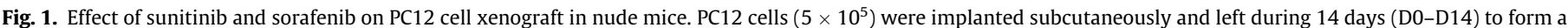

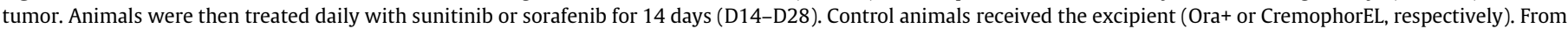

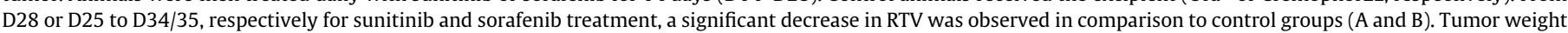

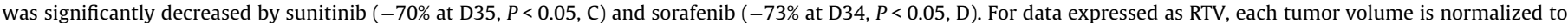
D14. $\bullet$, Ora+ control animals; $\mathbf{\square}$, CremophorEL control animals; $\nabla$, sunitinib-treated mice; $\Delta$, sorafenib-treated mice. ${ }^{*} P<0.05$, ${ }^{* * *} P<0.01$ and ${ }^{* * * *} P<0.001$.

\section{Discussion}

Currently, no curative treatment options are available for malignant PCC. An important feature of these malignant tumors and all VHL and SDHx-associated tumors in general is their hypervascularization, which suggests that anti-angiogenic drugs could represent efficient treatments [12,26-28]. Recently, a clinical study and case reports of oral administration of sunitinib showed promising results in patients with PCC or paraganglioma $[21,29,30]$. In particular, Ayala-Ramirez et al. reported several benefits of sunitinib in some patients with progressive metastatic pheochromocytoma in terms of tumor size reduction and disease stabilization [21]. Moreover, the approval of sunitinib use for pancreatic neuroendocrine tumors [31] also supports the idea that anti-angiogenic therapy could be effective in other neuroendocrine neoplasms. Due to its ability to directly inhibit the raf protein kinase in addition to RTKs, sorafenib also represents an interesting therapeutic tool. In fact, this anti-angiogenic drug has never been evaluated for PCC treatment. Therefore, in the present study, we investigated and compared for the first time the effect of sunitinib and sorafenib in a xenograft model of PCC. We demonstrated that after two weeks of oral administration in mice, both drugs were highly effective on PC12 cell xenograft tumors, with a drastic reduction of tumor growth and volume, accompanied by impaired angiogenesis.

Since no suitable human PCC cell line was available, we used the rat PC12 cell line to generate a model system of PCC in a xenograft. Injection of PC12 cells in nude mice led to tumor development with a comparable growth curve to that previously described using a similar xenograft model [32]. Treatment with sunitinib or sorafenib strongly slowed down tumor growth with no difference in potency and efficacy. Using a different administration mode (intravenous), Maitani et al. described a similar efficacy of sunitinib in another PC12 cell xenograft model [33]. Interestingly, the extent of tumor volume inhibition observed in our study was similar to that reported for sunitinib and sorafenib, used at comparable doses, in a xenograft model of human renal cell carcinoma [24].

Endothelial staining showed a very dense, irregular and tortuous vascular architecture in PC12 cell xenograft slices, which is reminiscent of the hypervascularization observed in malignant pheochromocytoma [9]. After two weeks of treatment with each compound, we found a significant and dramatic decrease in the parameters characterizing tumoral neo-angiogenesis, i.e. microvascular area, length and number of branches, and the number of 
A

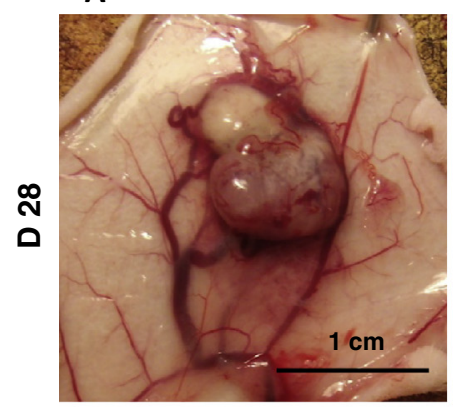

D

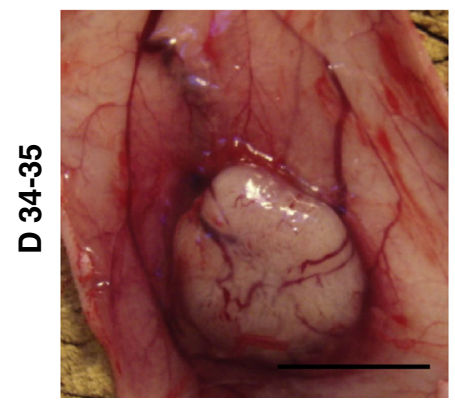

Control
B

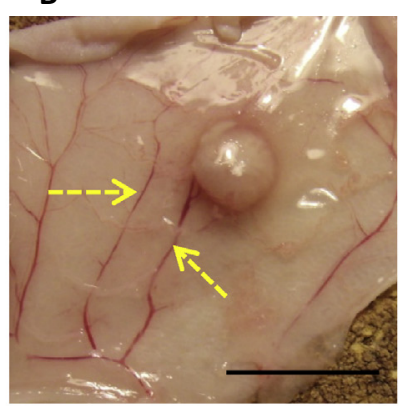

E

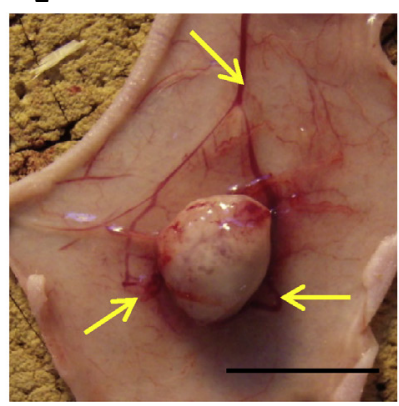

Sunitinib

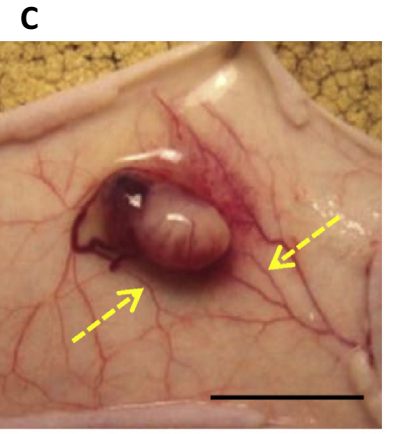

F

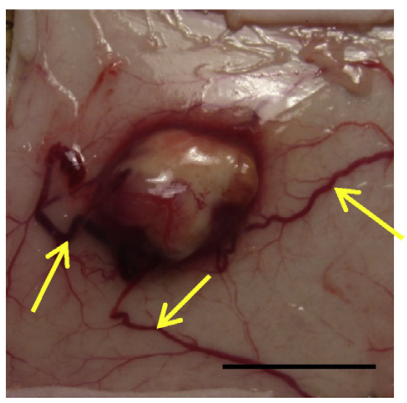

Sorafenib

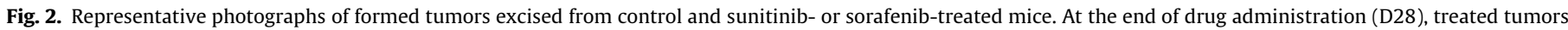

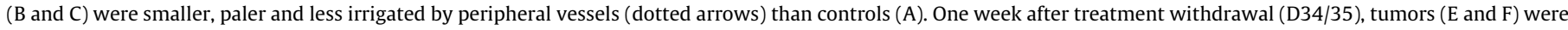
still smaller and less irrigated than controls (D) but thicker vessels were observed (arrows). Scale bar, $1 \mathrm{~cm}$.

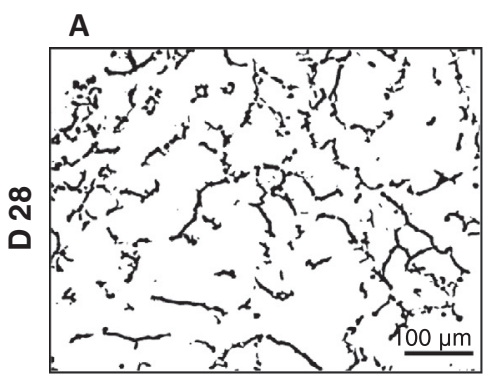

B
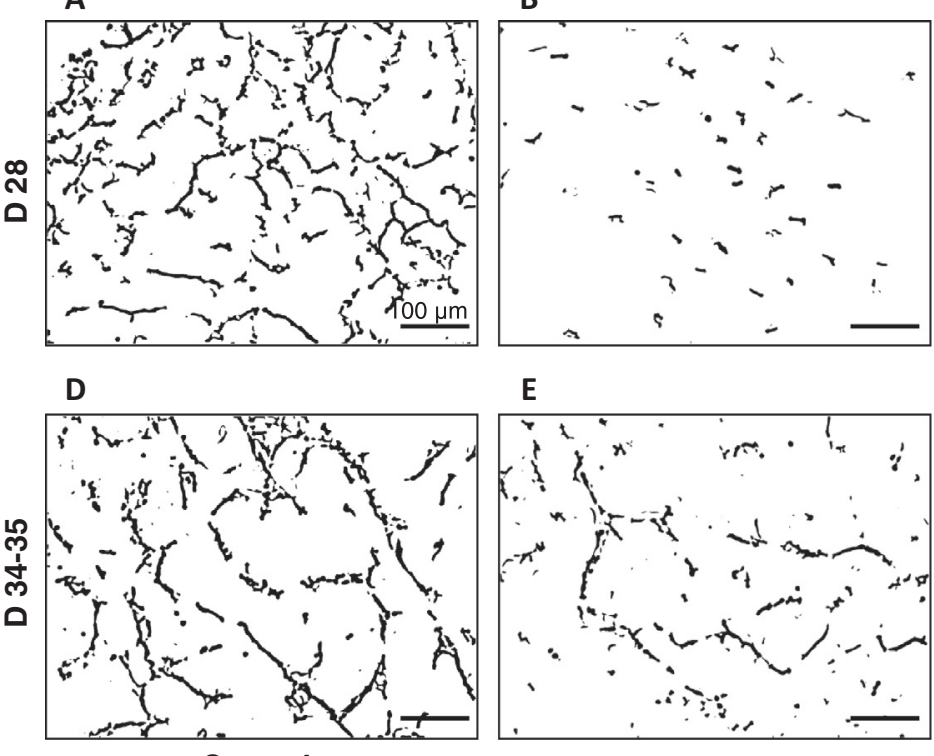

Control

\section{E}

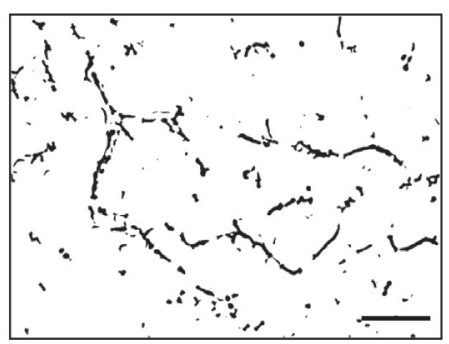

Sunitinib

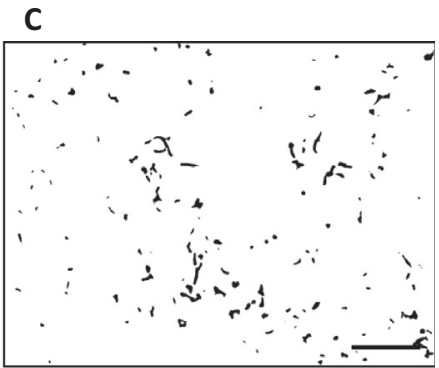

F

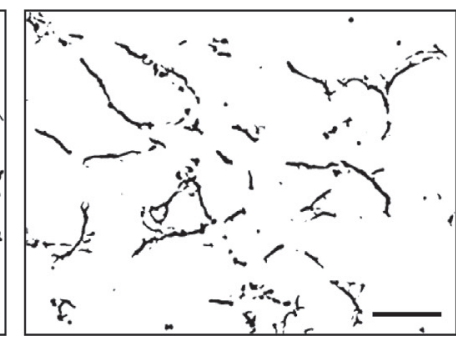

Sorafenib

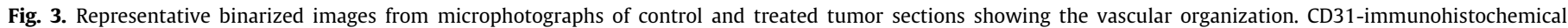

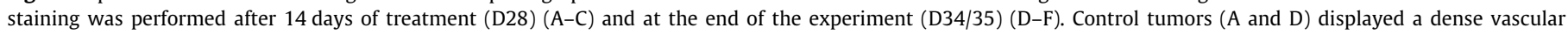

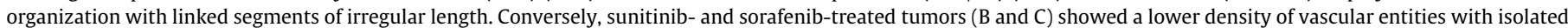

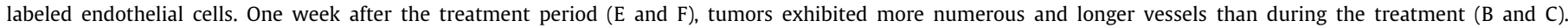
Magnification, $20 \times$.

nodes. Therefore, both drugs were able to inhibit vessel sprouting leading to decreased tumor growth. These observations suggest that sunitinib and sorafenib most likely act on common targets such as VEGFR-2, a major effector of neo-angiogenesis, to inhibit blood vessel formation in pheochromocytoma. The effect of sunitinib on the microvascular density was comparable to that observed in renal cell carcinoma xenografts [34]. However, treatment interruption provoked a rapid regrowth of tumor vessels, as has also been observed in lung carcinoma after withdrawal of a VEGF inhibitor [35], suggesting that a continuous treatment with these drugs is necessary to maintain the therapeutic effect. Such continuous treatment may provoke some toxic effects which should be 
A

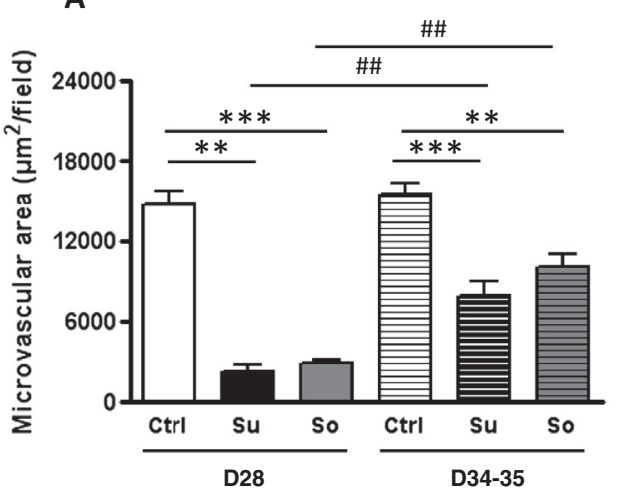

C
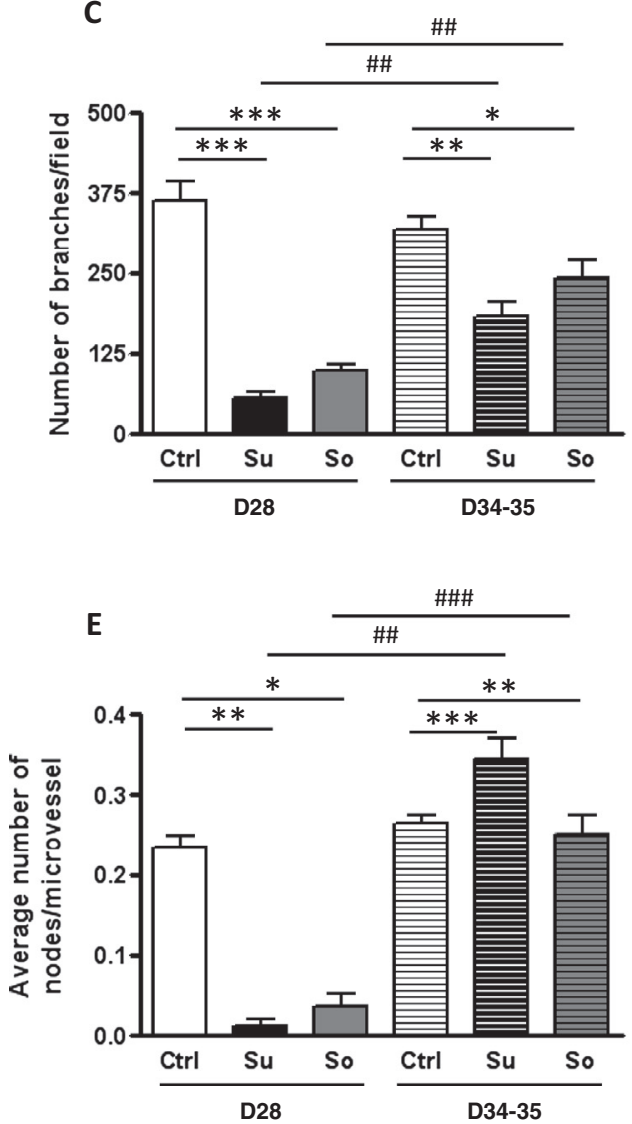

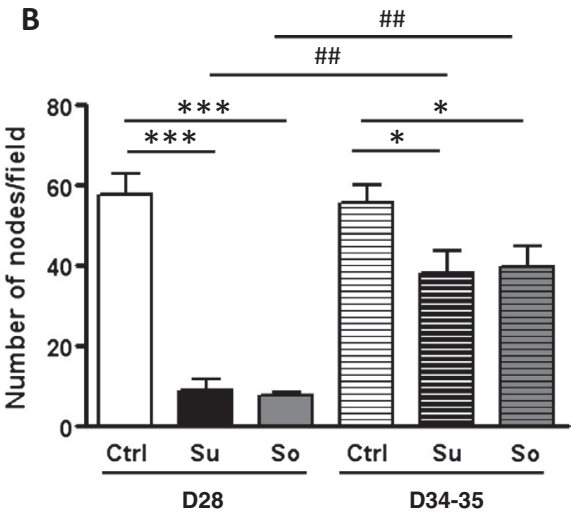

D
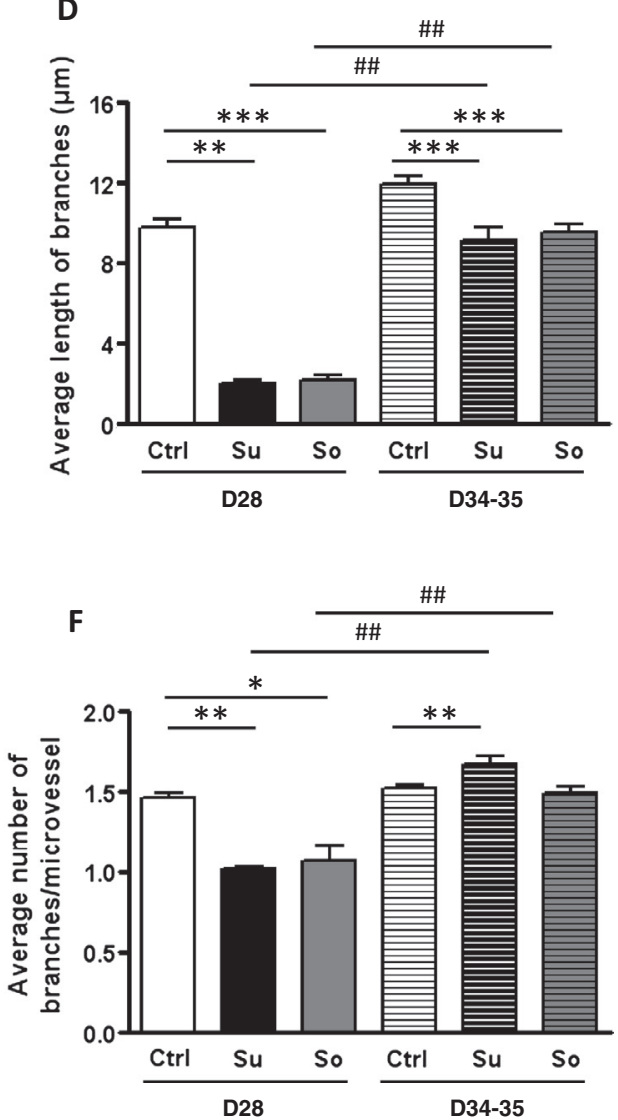

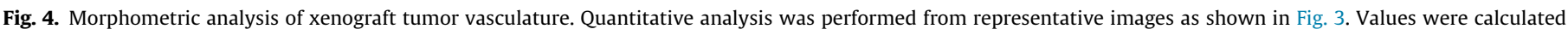

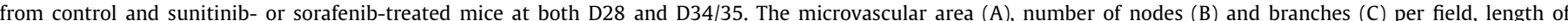

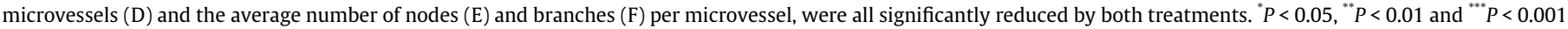
for controls vs. treated comparisons; ${ }^{\# \#} P<0.01$, ${ }^{\# \# P} P<0.001$ for D28-treated vs. D34/35-treated animals.

taken in consideration. We also observed a strong apoptosis after treatment with both drugs, although sunitinib seems to be a more potent effector of apoptosis than sorafenib in vivo. Other studies have reported that sunitinib and sorafenib could potently accelerate metastatic tumor growth after several weeks of treatment in xenograft-bearing mice [36-38]. Such a side effect was not observed in our model but additional studies using another PCC cell line with a malignant behavior, i.e. the MTT cell line [39] should be undertaken to test this possibility.

Besides their anti-angiogenic properties, we also demonstrated that both compounds had a direct effect on PC12 cells, in accordance with the expression of VEGFR-1, VEGFR-2, raf and RET in these cells [40-42]. Indeed, both sunitinib and sorafenib decreased cell viability within the nanomolar range, indicating that the VEGF signaling pathway exerts a pro-tumoral effect in pheochromocytoma in an autocrine manner. As shown by their IC50, it appears that both drugs are more potent in PC12 cells (sunitinib IC50 $=0.07 \mu \mathrm{M}$; sorafenib IC50 $=0.02 \mu \mathrm{M}$ ) than in renal carcinoma cell lines (sunitinib IC50 2-3 $\mu \mathrm{M}$; sorafenib IC50 0.3-3 $\mu \mathrm{M}$ ) [24]. Interestingly, the efficient concentrations described here for PC12 cell growth inhibition (sunitinib IC50 $37 \mathrm{ng} / \mathrm{mL}$ and sorafenib IC50 $13 \mathrm{ng}$ / $\mathrm{mL}$ ) are lower than the mean plasma concentration (sunitinib $60-100 \mathrm{ng} / \mathrm{mL}$ [43] and sorafenib 5-7 $\mu \mathrm{g} / \mathrm{mL}$ [44]) usually reported in treated patients, suggesting that the direct effects observed in vitro may also occur in vivo and would improve the efficacy of the drugs. The decrease in the number of cells could be ascribed to anti-proliferative and pro-apoptotic effects of these drugs. Thus, sunitinib could exert an anti-proliferative effect at low doses and 
A
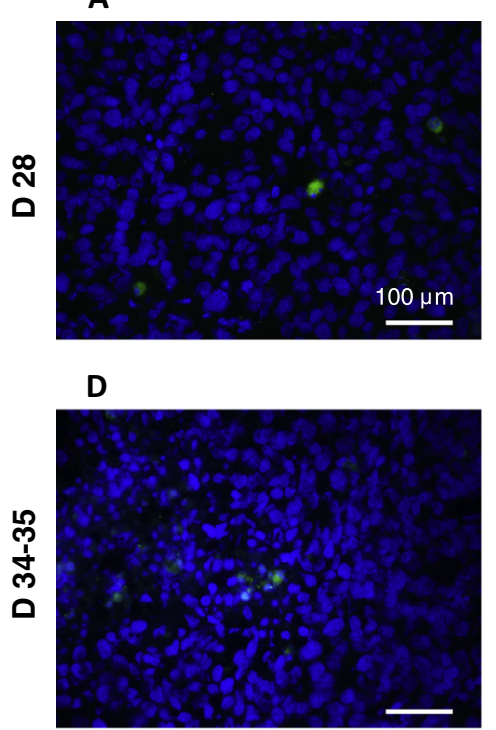

Control
B

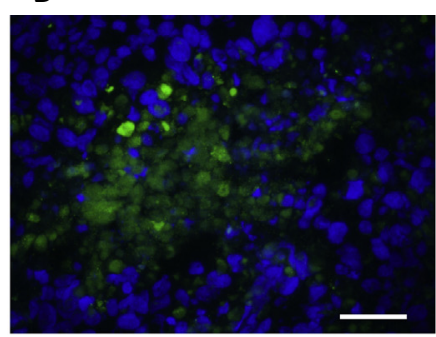

E

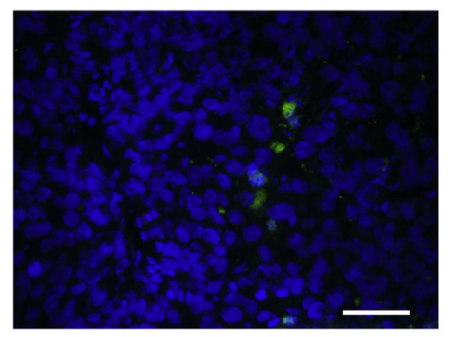

Sunitinib

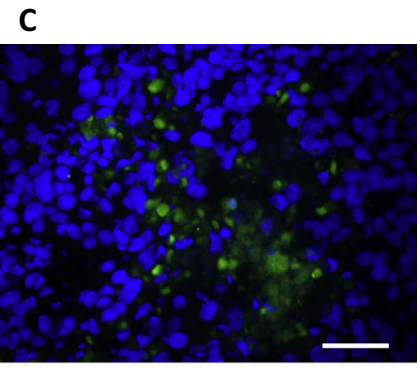

$\mathbf{F}$

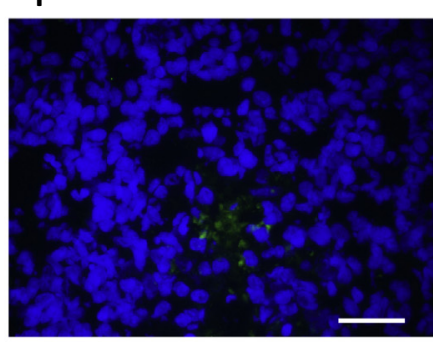

Sorafenib

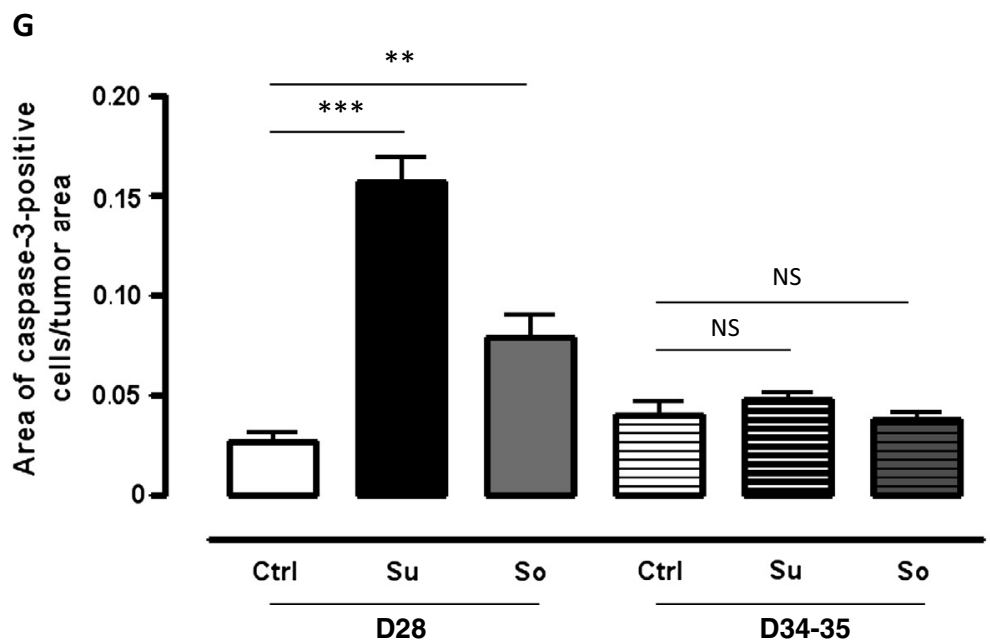

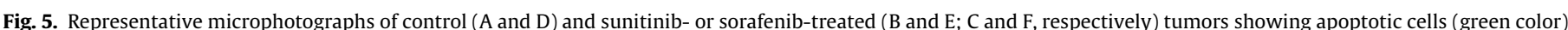

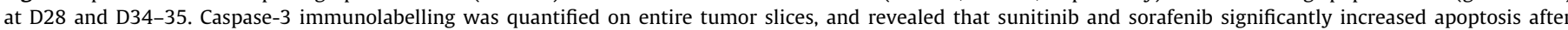

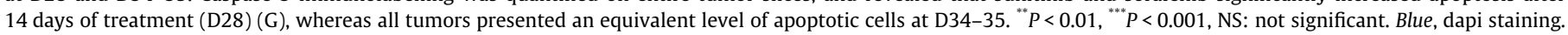

an apoptotic action at higher doses. In support of this hypothesis, we found that this drug exerted a potent pro-apoptotic effect at $30 \mu \mathrm{M}$ but not at 3 or $10 \mu \mathrm{M}$, although the latter concentrations were effective in decreasing the number of cells. These observations are consistent with those of Saito et al. showing the pro-apoptotic effect of sunitinib in PC12 cells [42]. Whether the anti-proliferative effect of sunitinib in PC12 cells is also attributable to a down-regulation of the AKT/mTOR pathway following VEGFR-2 inhibition as has been shown for its pro-apoptotic action [42] remains to be established.

Although both drugs triggered tumoral cell death when administered in vivo, sorafenib, unlike sunitinib, did not exert any apoptotic effect in vitro as assessed by a caspase-3/7 activity test in PC12 cells after treatment. Interestingly, recent studies conducted on hepatocellular carcinoma or lymphoma cells also revealed a weak and inconstant apoptotic activity of sorafenib depending on the cell line $[45,46]$. It should be noted that sorafenib directly inhibits RAS/RAF/MAPK pathway which can incidentally activate the phosphorylation of AKT [47], leading to a compensatory cell survival mechanism. Nevertheless, sorafenib exerted a cytotoxic effect in PC12 cells which could be ascribed to a caspase-3/7-independent cell death. It would be interesting to determine whether administration of PI3K/AKT inhibitors such as PI-103 could improve the inhibitory effect of sorafenib on pheochromocytoma tumor growth. If this were the case, sorafenib in combination with PI-103 would represent a better treatment than sorafenib or sunitinib alone, as synergistic or combinatorial effects of agents targeting several pathways are more likely to be effective in the long term [48].

In conclusion, our data obtained using a PCC model in vivo, provide strong pre-clinical evidence supporting the use of anti-angiogenic therapies in pheochromocytoma. We demonstrated a dual effect of both sunitinib and sorafenib to inhibit angiogenesis and tumoral cell survival in a pheochromocytoma xenograft model. While sunitinib efficacy has already been reported in a clinical study, our results indicate that sorafenib alone or in combination with other drugs targeting relevant pathways could also represent effective treatments for PCC. These treatments could be proposed at least for certain PCC subtypes characterized by heightened 
A

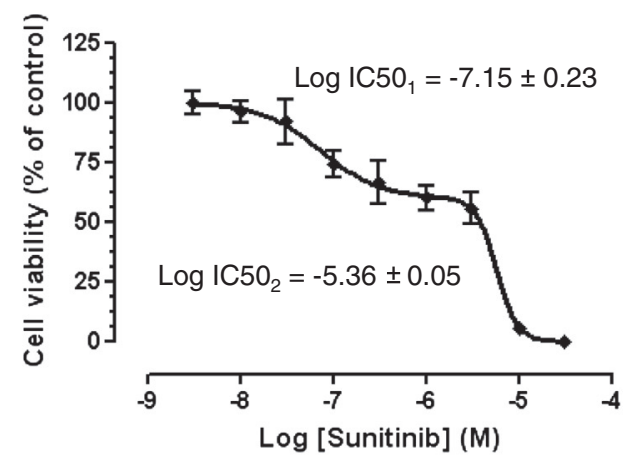

C

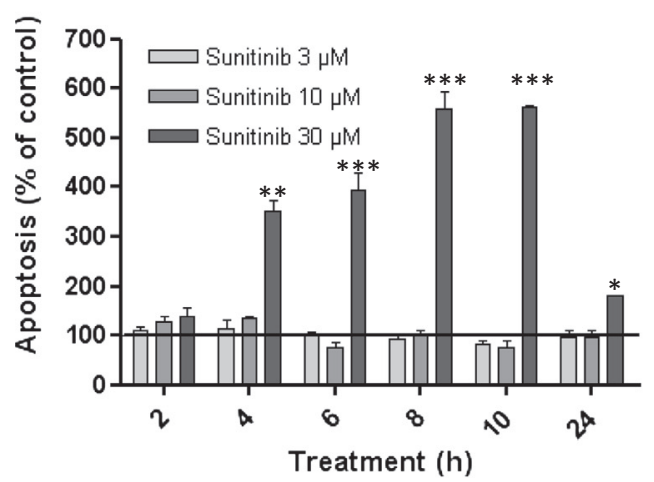

B

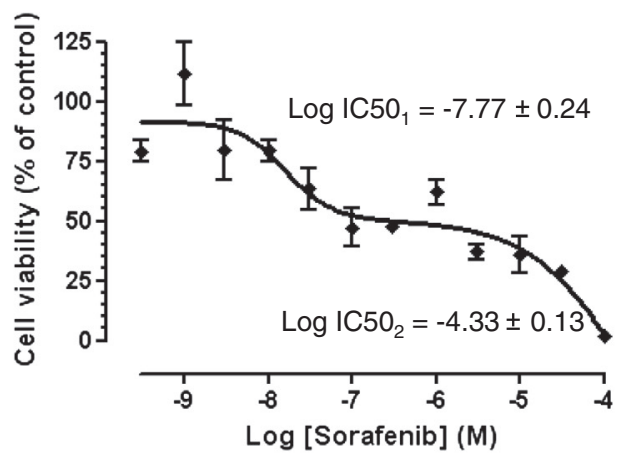

D

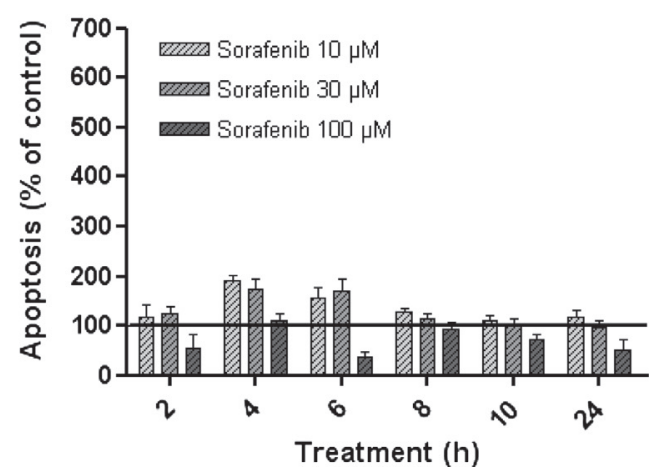

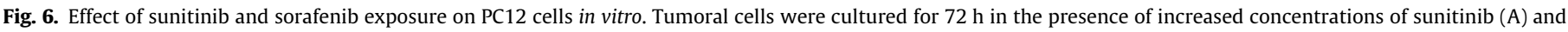

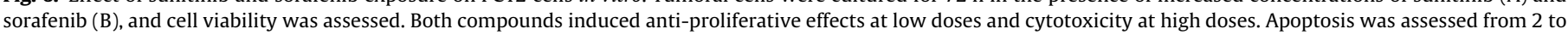

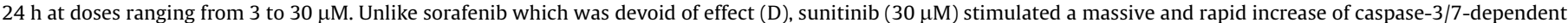
PC12 cell apoptosis (C). ${ }^{*} P<0.05,{ }^{* *} P<0.01$ and ${ }^{* * *} P<0.001$.

angiogenesis, such as malignant tumors and SDHx- and VHL-associated tumors in general.

\section{Conflict of Interest}

None declared.

\section{Acknowledgments}

We thank David Godefroy at the Vision Institute of Paris for his technical assistance with the scan of tumor slices, Damien Shapman for his technical assistance with image analysis and Patrice Bizet for helping with animals. Images were obtained on PRIMACEN (http://primacen.crihan.fr), the Cell Imaging Platform of Normandy.

\section{References}

[1] V. Kantorovich, K. Pacak, Pheochromocytoma and paraganglioma, Prog. Brain Res. 182 (2010) 343-373.

[2] L.J. Castro-Vega, A. Buffet, A.A. de Cubas, A. Cascón, M. Menara, E. Khalifa, L. Amar, S. Azriel, I. Bourdeau, O. Chabre, M. Curras-Freixes, V. Franco-Vidal, M. Guillaud-Bataille, C. Simian, A. Morin, R. Leton, A. Gomez-Grana, P.J. Pollard, P. Rustin, M. Robledo, J. Favier, A.P. Gimenez-Roqueplo, Germline mutations in $\mathrm{FH}$ confer predisposition to malignant pheochromocytomas and paragangliomas, Hum. Mol. Genet. (2013) 2440-2446.

[3] L. Fishbein, K.L. Nathanson, Pheochromocytoma and paraganglioma: understanding the complexities of the genetic background, Cancer Genet. 205 (2012) 1-11.

[4] J. Favier, A.P. Gimenez-Roqueplo, Pheochromocytomas: the (pseudo)-hypoxia hypothesis, Best Pract. Res. Clin. Endocrinol. Metab. 24 (2010) 957-968.

[5] S. Nölting, A.B. Grossman, Signaling pathways in pheochromocytomas and paragangliomas: prospects for future therapies, Endocr. Pathol. 23 (2012) 21-33.
[6] C. Jimenez, E. Rohren, M.A. Habra, T. Rich, P. Jimenez, M. Ayala-Ramirez, E. Baudin, Current and future treatments for malignant pheochromocytoma and sympathetic paraganglioma, Curr. Oncol. Rep. 15 (2013) 356-371.

[7] L. Amar, Genetic testing in pheochromocytoma or functional paraganglioma, J. Clin. Oncol. 23 (2005) 8812-8818.

[8] M. Ayala-Ramirez, L. Feng, M.M. Johnson, S. Ejaz, M.A. Habra, T. Rich, N. Busaidy, G.J. Cote, N. Perrier, A. Phan, S. Pate, S. Waquespack, C. Jimenez, Clinical risk factors for malignancy and overall survival in patients with pheochromocytomas and sympathetic paragangliomas: primary tumor size and primary tumor location as prognostic indicators, J. Clin. Endocrinol. Metab. 96 (2011) 717-725.

[9] J. Favier, P.F. Plouin, P. Corvol, J.M. Gasc, Angiogenesis and vascular architecture in pheochromocytomas: distinctive traits in malignant tumors, Am. J. Pathol. 161 (2002) 1235-1246.

[10] K. Salmenkivi, P. Heikkilä, J. Liu, C.A.J. Haglund, J. Arola, VEGF in 105 pheochromocytomas: enhanced expression correlates with malignant outcome, APMIS 111 (2008) 458-464.

[11] A. Zielke, M. Middeke, S. Hoffmann, M. Colombo-Benkmann, P. Barth, I. Hassan, A. Wunderlich, C. Lorenz, Q.Y. Duh, EGF-mediated angiogenesis of human pheochromocytomas is associated to malignancy and inhibited by anti-VEGF antibodies in experimental tumors, Surgery 132 (2002) 1056-1063.

[12] J. Favier, P. Igaz, N. Burnichon, L. Amar, R. Libé, C. Badoual, F. Tissier, J. Bertherat, P.F. Plouin, X. Jeunemaitre, A.P. Gimenez-Roqueplo, Rationale for anti-angiogenic therapy in pheochromocytoma and paraganglioma, Endocr. Pathol. 23 (2011) 34-42.

[13] Q. Liu, G. Djuricin, E.D. Staren, P. Gattuso, V.E. Gould, J. Shen, T. Saclarides, D.B. Rubin, R.A. Prinz, Tumor angiogenesis in pheochromocytomas and paragangliomas, Surgery 120 (1996) 938-942.

[14] P.P. Rooijens, R.R. de Krijger, H.J. Bonjer, F. van der Ham, A.L. Nigg, H.A. Bruining, S.W. Lamberts, E. Harst, The significance of angiogenesis in malignant pheochromocytomas, Endocr. Pathol. 15 (2004) 39-45.

[15] K.J. Gotink, H.M.W. Verheul, Anti-angiogenic tyrosine kinase inhibitors: what is their mechanism of action?, Angiogenesis 13 (2009) 1-14

[16] N.M. Hahn, M. Reckova, L. Cheng, L.A. Baldridge, O.W. Cummings, C.J. Sweeney, Patient with malignant paraganglioma responding to the multikinase inhibitor sunitinib malate, J. Clin. Oncol. 27 (2009) 460-463.

[17] C. Jimenez, M.E. Cabanillas, L. Santarpia, E. Jonasch, K.L. Kyle, E.A. Lano, S.F. Matin, R.F. Nunez, N.D. Perrier, A. Phan, T.A. Rich, B. Shah, M.D. Williams, S.G. Waguespack, Use of the tyrosine kinase inhibitor sunitinib in a patient with von Hippel-Lindau disease: targeting angiogenic factors in pheochromocytoma 
and other von Hippel-Lindau disease-related tumors, J. Clin. Endocrinol. Metab. 94 (2009) 386-391.

[18] A.M. Joshua, S. Ezzat, S.L. Asa, A. Evans, R. Broom, M. Freeman, J.J. Knox, Rationale and evidence for sunitinib in the treatment of malignant paraganglioma/pheochromocytoma, J. Clin. Endocrinol. Metab. 94 (2009) 5-9.

[19] F. Sun, H. He, T. Su, W. Zhou, X. Huang, J. Dai, Z.J. Shen, Multi-targeted tyrosine kinase inhibitor sunitinib: a novel strategy for sporadic malignant pheochromocytoma, Chin. Med. J. 125 (2012) 2231-2234.

[20] K.S. Park, J.L. Lee, H. Ahn, J.M. Koh, I. Park, J.S. Choi, Y.R. Kim, T.S. Park, J.H. Ahn, D.H. Lee, T.W. Kim, J.S. Lee, Sunitinib, a novel therapy for anthracycline- and cisplatin-refractory malignant pheochromocytoma, Jpn. J. Clin. Oncol. 39 (2009) 327-331.

[21] M. Ayala-Ramirez, C.N. Chougnet, M.A. Habra, J.L. Palmer, S. Leboulleux, M.E. Cabanillas, C. Caramella, P. Anderson, A. Al Ghuzlan, S.G. Waguespack, D. Deandreis, E. Baudin, C. Jimenez, Treatment with sunitinib for patients with progressive metastatic pheochromocytomas and sympathetic paragangliomas, J. Clin. Endocrinol. Metab. 97 (2012) 4040-4050.

[22] D.B. Mendel, A.D. Laird, X. Xin, S.G. Louie, J.G. Christensen, G. Li, R.E. Schreck, T.J. Abrams, T.J. Ngai, L.B. Lee, L.J. Murray, J. Carver, E. Chan, K.G. Moss, J.O. Haznedar, J. Sukbuntherng, R.A. Blake, L. Sun, C. Tang, T. Miller, S. Shirazian, G. McMahon, J.M. Cherrington, In vivo antitumor activity of SU11248, a novel tyrosine kinase inhibitor targeting vascular endothelial growth factor and platelet-derived growth factor receptors determination of a pharmacokinetic/ pharmacodynamic relationship, Clin. Cancer Res. 9 (2003) 327-337.

[23] Y.S. Chang, J. Adnane, P.A. Trail, J. Levy, A. Henderson, D. Xue, E. Bortolon, M. Ichetovkin, C. Chen, A. McNabola, D. Wilkie, C.A. Carter, I.C. Taylor, M. Lynch, S. Wilhelm, Sorafenib (BAY 43-9006) inhibits tumor growth and vascularization and induces tumor apoptosis and hypoxia in RCC xenograft models, Cancer Chemother. Pharmacol. 59 (2007) 561-574.

[24] M. Miyake, S. Anai, K. Fujimoto, S. Ohnishi, M. Kuwada, Y. Nakai, T. Inoue, A. Tomioka, N. Tanaka, Y. Hirao, 5-Fluorouracil enhances the antitumor effect of sorafenib and sunitinib in a xenograft model of human renal cell carcinoma, Oncol. Lett. 3 (2012) 1195-1202.

[25] J. Schindelin, I. Arganda-Carreras, E. Frise, V. Kaynig, M. Longair, T. Pietzsch, S. Preibisch, C. Rueden, S. Saalfeld, B. Schmid, J.Y. Tivenez, D.J. White, V. Hartenstein, K. Eliceiri, P. Tomancak, A. Cardona, Fiji: an open-source platform for biological-image analysis, Nat. Meth. 9 (2012) 676-682.

[26] K.E. Oberg, O. Casanovas, J.P. Castano, D.C. Chung, G. Delle Fave, P. Denefle, P. Harris, M.S. Khan, M.H. Kulke, A. Scarpa, L.H. Tang, B. Wiedenmann, Molecular pathogenesis of neuroendocrine tumors: implications for current and future therapeutic approaches, Clin. Cancer Res. 19 (2013) 2842-2849.

[27] G. Parenti, B. Zampetti, E. Rapizzi, T. Ercolino, V. Giachè, M. Mannelli, Updated and new perspectives on diagnosis, prognosis, and therapy of malignant pheochromocytoma/paraganglioma, J. Oncol. 2012 (2012) 1-10.

[28] S. Nölting, A. Giubellino, Y. Tayem, K. Young, M. Lauseker, P. Bullova, J. Schovanek, M. Anver, S. Fliedner, M. Korbonits, B. Göke, G. Vlotibes, A. Grossman, K. Pacak, Combination of 13-cis retinoic acid and lovastatin: marked antitumor potential in vivo in a pheochromocytoma allograft model in female athymic nude mice, Endocrinology 155 (2014) 2377-2390.

[29] M.E. Bourcier, A.I. Vinik, Sunitinib for the treatment of metastatic paraganglioma and vasoactive intestinal polypeptide-producing tumor (VIPoma), Pancreas 42 (2013) 348-352.

[30] T. Prochilo, G. Savelli, P. Bertocchi, C. Abeni, L. Rota, A. Rizzi, A. Zaniboni, Targeting VEGF-VEGFR pathway by sunitinib in peripheral primitive neuroectodermal tumor, paraganglioma and epithelioid hemangioendothelioma: three case reports, Case Rep. Oncol. 6 (2013) 90-97.

[31] M.H. Kulke, J. Bendell, L. Kvols, J. Picus, R. Pommier, J. Yao, Evolving diagnostic and treatment strategies for pancreatic neuroendocrine tumors, J. Hematol. Oncol. 4 (2011) 29.

[32] A. Zielke, R.S. Bresalier, A.E. Siperstein, O.H. Clark, M. Rothmund, Q.Y. Duh, A unique allogenic model of metastatic pheochromocytoma: PC12 rat pheochromocytoma xenografts to nude mice and establishment of metastases-derived PC12 variants, Clin. Exp. Metast. 16 (1998) 341-352.

[33] Y. Maitani, H. Saito, Y. Seishi, Y. Iwase, T. Yamauchi, K. Higashiyama, T. Sugino, A combination of liposomal sunitinib plus liposomal irinotecan and liposome co-loaded with two drugs enhanced antitumor activity in PC12-bearing mouse, J. Drug Target. 20 (2012) 873-882.

[34] D. Huang, Y. Ding, Y. Li, W.M. Luo, Z.F. Zhang, J. Snider, K. Vandenbeldt, C.N Qian, B.T. Teh, Sunitinib acts primarily on tumor endothelium rather than tumor cells to inhibit the growth of renal cell carcinoma, Cancer Res. 70 (2010) 1053-1062.

[35] M.R. Mancuso, R. Davis, S.M. Norberg, S. O’Brien, B. Sennino, T. Nakahara, V.J Yao, T. Inai, P. Brooks, B. Freimark, D.R. Shalinsky, D.D. Hu-Lowe, D.M. McDonald, Rapid vascular regrowth in tumors after reversal of VEGF inhibition, J. Clin. Invest. 116 (2006) 2610-2621.

[36] J.M.L. Ebos, C.R. Lee, R.S. Kerbel, Tumor and host-mediated pathways of resistance and disease progression in response to antiangiogenic therapy, Clin. Cancer Res. 15 (2009) 5020-5025.

[37] M. Pàez-Ribes, E. Allen, J. Hudock, T. Takeda, H. Okuyama, F. Viñals, M. Inoue G. Bergers, D. Hanahan, O. Casanovas, Antiangiogenic therapy elicits malignant progression of tumors to increased local invasion and distant metastasis, Cancer Cell 15 (2009) 220-231.

[38] W. Zhang, H. Sun, W. Wang, Q. Zhang, P. Zhuang, Y. Xiong, Sorafenib downregulates expression of HTATIP2 to promote invasiveness and metastasis of orthotopic hepatocellular carcinoma tumors in mice, Gastroenterology 143 (2012) 1641-1649.

[39] L. Martiniova, E.W. Lai, A.G. Elkahloun, M. Abu-Asab, A. Wickremasinghe, D.C Solis, S.M. Perera, T.T. Huynh, I.A. Lubensky, A.S. Tischler, R. Kvetnansky, S. Alesci, J.C. Morris, K. Pacak, Characterization of an animal model of aggressive metastatic pheochromocytoma linked to a specific gene signature, Clin. Exp. Metast. 26 (2009) 239-250.

[40] G.D. Vita, R.M. Melillo, F. Carlomagno, R. Visconti, M.D. Castellone, A. Bellacosa, M. Billaud, A. Fusco, P.N. Tsichlis, M. Santoro, Tyrosine 1062 of RET-MEN2A mediates activation of Akt (Protein Kinase B) and mitogen-activated protein kinase pathways leading to PC12 cell survival, Cancer Res. 60 (2000) $3727-$ 3731.

[41] P. Peraldi, M. Frödin, J.V. Barnier, V. Calleja, J.C. Scimeca, C. Filloux, G. Calothy, E. Van Obberghen, Regulation of the MAP kinase cascade in PC12 cells: B-raf activates MEK-1 (MAP kinase or ERK kinase) and is inhibited by CAMP, FEBS Lett. 357 (1995) 290-296.

[42] Y. Saito, Y. Tanaka, Y. Aita, K. Ishii, T. Ikeda, K. Isobe, Y. Kawakami, H. Shimano, H. Hara, K. Takekoshi, Sunitinib induces apoptosis in pheochromocytoma tumor cells by inhibiting VEGFR2/Akt/mTOR/S6K1 pathways through modulation of Bcl-2 and BAD, Am. J. Physiol. Endocrinol. Metab. 302 (2012) 615-625.

[43] N.A. Lankheet, L.M. Knapen, J.H. Schellens, J.H. Beijnen, N. Steeghs, A.D. Huitema, Plasma concentrations of tyrosine kinase inhibitors imatinib, erlotinib, and sunitinib in routine clinical outpatient cancer care, Ther. Drug Monit. 36 (2013) 326-334.

[44] D. Strumberg, H. Richly, R.A. Hilger, N. Schleucher, S. Korfee, M. Tewes, M Faghih, E. Brendel, D. Voliotis, C.G. Haase, B. Schwartz, A. Awada, R. Voigtmann, M.E. Scheulen, S. Seeber, Phase I clinical and pharmacokinetic study of the novel raf kinase and vascular endothelial growth factor receptor inhibitor BAY 43-9006 in patients with advanced refractory solid tumors, J. Clin. Oncol. 23 (2005) 965-972.

[45] A. Galmiche, B. Chauffert, J.-C. Barbare, New biological perspectives for the improvement of the efficacy of sorafenib in hepatocellular carcinoma, Cancer Lett. 346 (2013) 159-162.

[46] C. Carlo-Stella, S.L. Locatelli, A. Giacomini, L. Cleris, E. Saba, M. Righi, A Guidetti, A.M. Gianni, Sorafenib inhibits lymphoma xenografts by targeting MAPK/ERK and AKT pathways in tumor and vascular cells, PLoS ONE 8 (2013) e61603.

[47] R. Gedaly, P. Angulo, C. Chen, K.T. Creasy, B.T. Spear, J. Hundley, M.F. Daily, M. Shah, B.M. Evers, The role of PI3K/mTOR inhibition in combination with sorafenib in hepatocellular carcinoma treatment, Anticancer Res. 32 (2012) 2531-2536.

[48] S. Nölting, E. Garcia, G. Alusi, A. Giubellino, K. Pacak, M. Korbonits, A.B. Grossman, Combined blockade of signalling pathways shows marked antitumour potential in phaeochromocytoma cell lines, J. Mol. Endocrinol. 49 (2012) 79-96. 